\title{
Migration and mortality: a 20 year follow up of Finnish twin pairs with migrant co-twins in Sweden
}

\author{
N Hammar, J Kaprio, U Hagström, L Alfredsson, M Koskenvuo, T Hammar
}

J Epidemiol Community Health 2002;56:362-366

See end of article for authors' affiliations

.....................

Correspondence: Dr N Hammar, Department of Epidemiology, Karolinska Hospital, Norrbacka Building, S-171 76

Stockholm, Sweden; niklas.hammar@imm.ki.se

Accepted for publication 7 September 2001

\begin{abstract}
Study objective: Finland has a higher mortality overall and for major causes of death than Sweden, primarily in men. The objective of this study was to analyse mortality in migrants from Finland to Sweden.

Design: A longitudinal study based on the Finnish Twin Cohort Study. Information about migration from Finland to Sweden, duration of stay in Sweden for the migrants, and deaths 1976-1995 was obtained from national registers. Observed numbers of deaths in migrants were compared with expected numbers based on the age standardised mortality experience of the Finnish Twin Cohort. First deaths in migrants and non-migrants of migrant discordant pairs were compared controlling for genetic and early childhood factors.

Participants: Twin pairs of the Finnish Twin Cohort Study where at least one twin had migrated to Sweden (1542 twin pairs).

Main results: Among men, migrants from Finland to Sweden showed an overall similar mortality compared with all subjects of the Finnish Twin Cohort (SMR 1.1; $95 \% \mathrm{Cl} 0.9$ to 1.4). Mortality from nonviolent causes was increased for migrants with at most 20 years in Sweden (SMR 1.9; 95\% Cl 1.2 to 2.6) and decreased in those with a longer stay (SMR 0.7; 95\% Cl 0.4 to 0.9). Similar results were obtained concerning first deaths in twin pairs discordant for migration. Among women, migrants had an increased mortality overall (SMR 1.4; $95 \% \mathrm{Cl} 1.0$ to 1.8), from cardiovascular disease (SMR 1.7; $95 \% \mathrm{Cl} 1.0$ to 2.7 ), and from violent causes (SMR 2.5; $95 \% \mathrm{Cl} 1.2$ to 4.6 ) compared with all women of the Finnish Twin Cohort. In analyses of migrant discordant pairs only first deaths from cardiovascular disease tended to be more common in the migrants than in non-migrant co-twins.

Conclusions: Migrants from Finland to Sweden seem to have an overall mortality comparable to that prevailing in Finland suggesting no strong influence on mortality by the migration. Duration of stay seems to be associated with mortality in the migrants, at least in men, with a lower mortality after several years in Sweden.
\end{abstract}

nternational migration may imply changes in environment and behaviour that influence the risk of disease for the migrants. ${ }^{1-7}$ After the second world war large migration from Finland, basically labour migration, has resulted in a migrant population in Sweden of about 240000 Finnish born persons. Men in Finland have a considerably higher mortality overall and with regard to major causes of death than men in Sweden. ${ }^{8}$ Among women the mortality is higher in Finland than in Sweden but the differences are less pronounced. Finnish migrants in Sweden seem to have a poorer health than native Swedes with regard to cardiovascular, psychiatric as well as musculoskeletal diseases. ${ }^{9-11}$ An observed reduced incidence of myocardial infarction among migrants after several years in Sweden may indicate a favourable influence of long term changes in behavioural and environmental factors. ${ }^{12}$

Migrant studies take advantage of a "natural experiment" and may contribute to the understanding of how changes in environmental and behavioural factors influence the risk of disease. An observed lower mortality among migrants than in the population of the host country or of the population of the country from which they migrated ${ }^{13-15}$ may, however, in part be attributable to factors relating to decision to migrate or conditions for migration. The Finnish Twin Cohort Study ${ }^{16}$ includes many subjects that have moved from Finland to Sweden. Analysis of twin pairs where one twin has migrated to Sweden and the co-twin has stayed in Finland ("migrant discordant" pairs) has methodological advantages including that the migrant twin and the non-migrant co-twin share genetic factors and childhood environment. The aim of this study was to compare the mortality among migrants from Finland to Swe- den with that of non-migrants in Finland, using information from the Finnish Twin Cohort Study.

\section{METHODS}

The Finnish Twin Cohort Study was established in 1974 and consists of all same sexed twin pairs born in Finland before 1958 with both twins alive in 1975 ( $\mathrm{n}=13888$ twin pairs). ${ }^{16}$ All twins of the Finnish Twin Cohort Study who had migrated to Sweden before the end of 1993 were identified through the Central Population Register of Finland. Migrants were defined as persons at least once registered as residents in Sweden and non-migrants as persons not registered and remaining in Finland.

Swedish personal identification numbers were obtained through tax authorities by using information about date of birth and name. A date of migration, as well as of eventual re-migration to Finland, during 1968-1994 was obtained from Statistics Sweden. Information about residency in Sweden was obtained from the 1960 census, and from Swedish population registers by 31 December 1968 and 1978, and October 1995 respectively. In the analyses, migrants residing in Sweden since at least 1960 were assigned a duration of stay in Sweden of at least 20 years at the start of the study period (1976). Migrants, who were living in Sweden in 1968 but not in 1960, were assigned a duration in Sweden corresponding to migration in 1965.

A questionnaire was mailed to all twins of the Finnish Twin Cohort Study in 1975 including questions on health, lifestyle factors, occupation, working conditions, and socioeconomic 
Table 1 Number of twin pairs of the Finnish Twin Cohort study where at least one twin had migrated to Sweden. By sex and age at baseline in 1975

\begin{tabular}{|c|c|c|c|c|c|c|c|}
\hline \multirow[b]{2}{*}{ Age 1975} & \multicolumn{3}{|c|}{ One twin migrated } & \multicolumn{3}{|c|}{ Both twins migrated } & \multirow[b]{2}{*}{ Total } \\
\hline & Men & Women & All & Men & Women & All & \\
\hline$<30 y$ & 256 & 278 & 534 & 155 & 159 & 314 & 848 \\
\hline $30-39$ y & 196 & 142 & 388 & 56 & 33 & 89 & 427 \\
\hline $40-49 y$ & 72 & 60 & 132 & 21 & 18 & 39 & 171 \\
\hline$\geqslant 50 y$ & 36 & 50 & 86 & 4 & 6 & 10 & 96 \\
\hline Total & 560 & 530 & 1090 & 236 & 216 & 452 & 1542 \\
\hline
\end{tabular}

factors. ${ }^{16}{ }^{17}$ The response rate was $89 \%$, but only $47 \%$ for migrants to Sweden and $56 \%$ for migrants of migrant discordant pairs. Migrant discordant pairs where both members of the pair had responded to the 1975 questionnaire $(\mathrm{n}=570)$ were analysed with regard to several factors, many of which were measured by standard scales or instruments that have been described earlier. ${ }^{17} 18$

Information about deaths was collected for the period 1 January 1976 to 31 December 1995 through National Cause of Death Registers in the two countries. The analyses of mortality concerned death from all causes, cancer (International Classification of Diseases (ICD) 8 and ICD 9 code 140-239), cardiovascular diseases (ICD 8 code $390-458$ and ICD 9 code 390-459), coronary heart disease (ICD 8 and ICD 9 code 410414), violent causes - that is, accidents, suicides and homicides (ICD 8 and ICD 9 code E800-E999) and all non-violent causes (all causes except violent causes).

\section{Statistical analysis}

Migrants and non-migrants of migrant discordant pairs were compared regarding items of the 1975 questionnaire by percentage differences with $95 \%$ confidence intervals. The observed number of deaths among the migrants was compared with an expected number based on the sex and age (five year age groups) specific mortality of all members of the Finnish Twin Cohort Study during 1976-1995 by standardised mortality ratios (SMR), with $95 \%$ confidence intervals. The observed number of cases was assumed to follow a Poisson distribution. Person years were calculated beginning at the start of the follow up 1 January 1976 or at the time of first migration to Sweden whichever came later, and ended 31
December 1995, at the time of first migration back to Finland or at the time of death, whichever came first. Analyses were also performed where migrants returning to Finland were followed up after re-migration.

For migrant discordant pairs first deaths within the pair were determined. In these analyses the follow up was ended for both members of the pair 31 December 1995, at the time of first migration back to Finland or when the first one died, whichever came first. The proportion of all first deaths that occurred among migrants was calculated together with a 95\% confidence interval based on the binomial distribution.

\section{RESULTS}

In all, 1994 migrants to Sweden were identified in the Finnish Twin Cohort Study belonging to 1542 twin pairs of which 1090 "migrant discordant" pairs (table 1). The time of first migration to Sweden and the length of time spent in Sweden were determined for 1925 subjects $(97 \%)$.

\section{Baseline data from the 1975 questionnaire}

For most items of the 1975 questionnaire there were small differences between the migrant and the non-migrant (table 2 ). The proportion of blue collar workers tended to be higher among migrants and among men this also concerned a comparatively high alcohol consumption. Among women, smoking and physically heavy labour was more common among migrants and work disabling back pain, neck pain or shoulder pain less common.

Table 2 Characteristics of migrants and non-migrants of migrant discordant pairs of the Finnish Twin Cohort Study. Data from questionnaire at baseline in 1975. Differences in proportions with $95 \%$ confidence intervals

\begin{tabular}{|c|c|c|c|c|c|c|c|c|}
\hline \multirow[b]{2}{*}{ Characteristics } & \multicolumn{4}{|c|}{ Men ( $n=246$ pairs) } & \multicolumn{4}{|c|}{ Women ( $n=324$ pairs) } \\
\hline & $\begin{array}{l}\text { Migrants } \\
\%\end{array}$ & $\begin{array}{l}\text { Non-migrants } \\
\%\end{array}$ & $\begin{array}{l}\text { Difference } \\
\%\end{array}$ & $95 \% \mathrm{Cl}$ & $\begin{array}{l}\text { Migrants } \\
\%\end{array}$ & $\begin{array}{l}\text { Non-migrants } \\
\%\end{array}$ & $\begin{array}{l}\text { Difference } \\
\%\end{array}$ & $95 \% \mathrm{Cl}$ \\
\hline Not married & 46 & 45 & 1 & -8 to 10 & 39 & 38 & 1 & -7 to 8 \\
\hline Highest education elementary school & 1 & 1 & 0 & -2 to 2 & 2 & 2 & 0 & -3 to 2 \\
\hline Current unemployment & 7 & 5 & 2 & -2 to 6 & 4 & 5 & -1 & -4 to 2 \\
\hline Blue collar worker & 67 & 60 & 7 & -2 to 16 & 50 & 42 & 8 & 0 to 16 \\
\hline Physically heavy work* & 61 & 58 & 3 & -6 to 12 & 53 & 44 & 9 & 1 to 17 \\
\hline Current smoker & 51 & 46 & 5 & -4 to 14 & 37 & 30 & 7 & 0 to 14 \\
\hline $\begin{array}{l}\text { Consumption of }>10 \mathrm{~g} \text { pure alcohol per } \\
\text { day }\end{array}$ & 48 & 38 & 10 & 1 to 19 & 9 & 10 & -1 & -6 to 3 \\
\hline Almost no exercise & 32 & 28 & 4 & -4 to 12 & 34 & 39 & -5 & -12 to 3 \\
\hline Use of sedatives or sleep pills & 9 & 5 & 4 & -1 to 8 & 14 & 12 & 2 & -3 to 7 \\
\hline Body mass index $>25$ & 21 & 22 & -1 & -9 to 6 & 14 & 13 & 1 & -4 to 7 \\
\hline $\begin{array}{l}\text { Work-disabeling back-neck- or shoulder } \\
\text { pain }\end{array}$ & 48 & 44 & 4 & -5 to 13 & 37 & 45 & -8 & -16 to 0 \\
\hline Angina pectoris & 3 & 3 & 0 & -4 to 3 & 2 & 4 & -2 & -5 to 1 \\
\hline Physician diagnosed hypertension & 9 & 9 & 0 & -6 to 5 & 10 & 12 & -2 & -6 to 4 \\
\hline Shortness of breath $\dagger$ & 26 & 24 & 2 & -6 to 9 & 43 & 43 & 0 & -8 to 7 \\
\hline Bronchitis & 4 & 6 & -2 & -5 to 3 & 5 & 6 & -1 & -4 to 3 \\
\hline
\end{tabular}




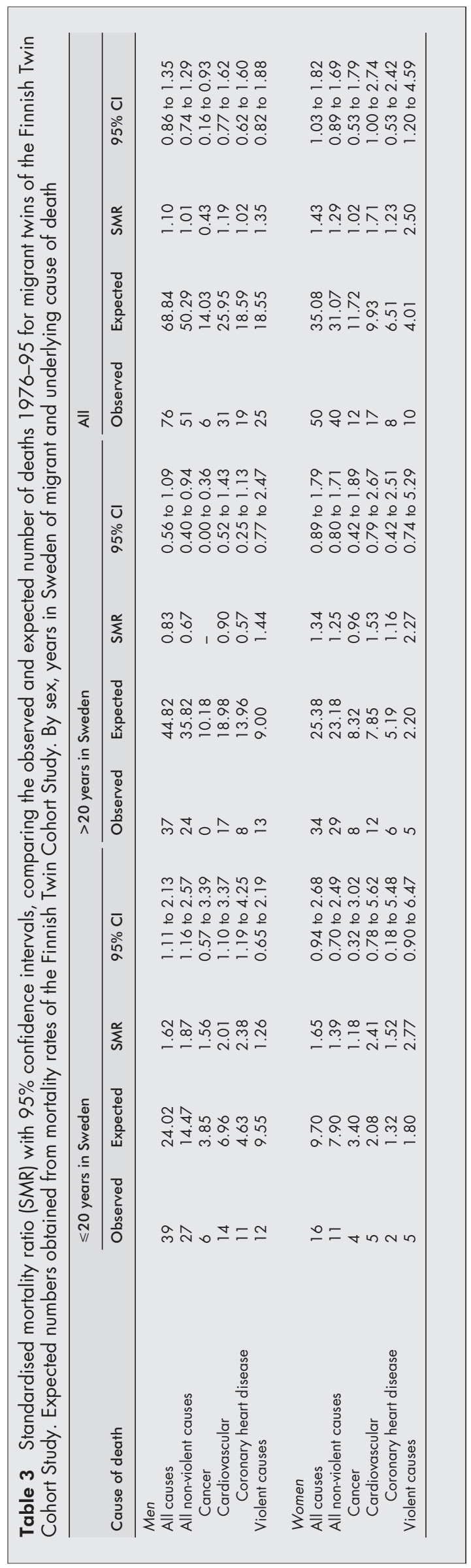

Comparison to mortality experience of the Finnish Twin Cohort

There were 126 deaths among the migrants during the follow up period, 76 among men and 50 among women (table 3 ). For men the observed number of deaths was close to that expected on the basis of the mortality experience of the Finnish Twin Cohort (SMR 1.10; 95\% CI 0.86 to 1.35). Among migrants with an estimated duration of stay in Sweden of at most 20 years there was a higher mortality than expected, primarily from all non-violent causes and from cardiovascular disease. For migrants with a longer duration of stay in Sweden mortality from non-violent causes was lower than expected. Including also the person time and deaths during the observation period in migrants returning to Finland gave similar results.

Among women the number of observed deaths in the migrants exceeded that expected based on the mortality experience of all women in the Finnish Twin Cohort Study (SMR 1.43; 95\% CI 1.03 to 1.82 ). This increase concerned primarily mortality from cardiovascular disease and from violent causes. Extending the analyses to include also time in Finland of re-migrants only marginally influenced the results.

\section{Comparison of first deaths in migrant discordant twin pairs}

The numbers of first deaths in twin pairs discordant for migration were similar between the migrants and the non-migrants among men (table 4; 33 of 74 first deaths in migrants). First deaths from all non-violent causes tended to be more common in migrants with an estimated time in Sweden of at most 20 years compared with non-migrant co-twins remaining in Finland. Fewer first deaths overall and from non-violent causes were found in migrants with more than 20 years in Sweden compared with their co-twins.

Also among women, the numbers of first deaths were similar between the migrant and the non-migrant co-twin (27 of 52 first deaths in migrants). First deaths from cardiovascular disease tended, however, to be more common in the migrants than in the co-twins in Finland.

\section{DISCUSSION}

The results of this study, in part based on comparisons within migrant discordant twin pairs controlling for genetic and early childhood factors, suggest that male migrants from Finland to Sweden have an overall mortality experience that is similar to that prevailing in Finland. Mortality from non-violent causes was, however, reduced in migrants with several years in Sweden. Among women an increased mortality from cardiovascular disease in migrants was observed. Consistent with previous observations, ${ }^{10}{ }^{11}$ these results suggest a higher mortality in migrants from Finland to Sweden than in native Swedes in view of the higher mortality in Finland than in Sweden.

The migrants were identified through population registers in Finland and almost all were found also in corresponding registers in Sweden. In order to be registered as a migrant in these registers it is necessary to officially move to Sweden, which is recorded at the latest at employment or when using social security. There are probably certain people in the Finnish Twin Cohort Study who have lived some time in Sweden without registration as a migrant and there may also be migrants that have returned to Finland for some period of time without registration of a new address. This misclassification of migration as well as of the time spent in Sweden is probably unrelated to mortality and probably did not substantially influence associations between migration and mortality. Migration, or return to Finland, that was not registered probably in general concerned short periods of time as a more permanent move, either to take up employment or to use social benefits, would entail an official change of address. The authorities in Finland and Sweden regularly exchange 


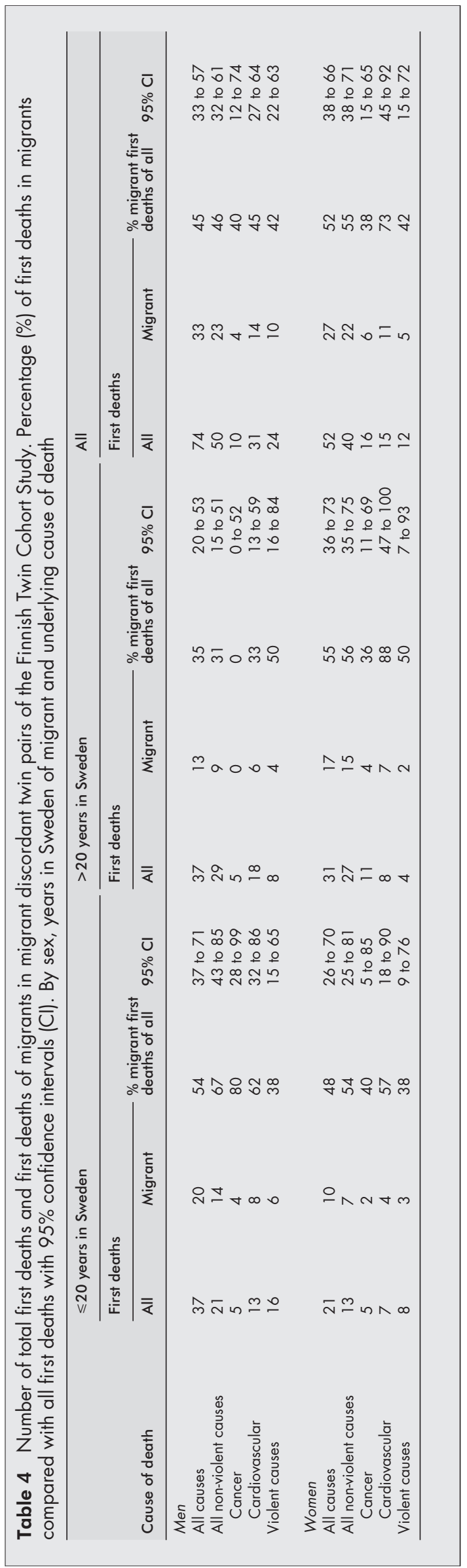

individual level information on migrants. There was essentially no loss of deaths in the national mortality registers of Finland and Sweden. Thus, information on all cause mortality is comparable between the two countries and this should also basically apply to the broad categories of causes of death used in the analyses of this study. A collaboration regarding classification and coding of causes of death in mortality statistics is going on among the Nordic countries and a recent evaluation showed an $80 \%$ agreement in coding of a sample of death certificates using ICD-10 at the three character level between Sweden and Finland. ${ }^{19}$

A strength of this study was the possibility to analyse mortality in migrant discordant twin pairs. In general, the twins of these pairs had a common childhood environment and also shared genetic factors. Questionnaire data from 1975 indicated that migrants and non-migrants were comparable in several respects at the start of the study period. It has been suggested that a low mortality in a migrant population in part may be attributable to a selective return to the country from which the migrants originated. ${ }^{13}$ We found that inclusion of the re-migrants had only marginal effect on the mortality of the migrant group. Interpretations of results from this study are, however, limited by the comparatively few deaths during the study period, in particular in comparisons of migrant discordant pairs.

A lower mortality from non-violent causes in men living for many years in Sweden was suggested by our findings and is in accordance with the results of a previous study of myocardial infarction incidence in migrants from Finland to Sweden. ${ }^{12}$ These findings could be related to long term changes in environmental and behavioural factors. It might be speculated that a decrease in mortality after several years in Sweden comes from a more full adaptation to the Swedish society with improved standard of living, social relations and networks and perhaps a different lifestyle. It is agreed in migration research that integration of a first generation migrant is a lifelong process, and that only members of second or third generations will be completely integrated..$^{20}$ We therefore expect that health consequences for the first generation of migrants will change over time, and that only after 20 years or more - that is, in very long term follow ups-can expect to see the final consequences. The results of this study are consistent with this general perspective, especially for men. Further analyses of the migrant twin cohort are presently being conducted focusing on behavioural and environmental changes after the migration as well as integration in Swedish society. These analyses will contribute to shed additional light on the extent to which migration may influence the long term health of migrants.

\section{ACKNOWLEDGEMENT}

The authors would like to thank Ms Gunnel Gråbergs for computer processing, Ms Lena Wärnlöf for taking part in the collection of information of Swedish personal identification numbers and Kauko Heikkilä, Phil.Lic. for database management of the Finnish Twin Cohort.

Funding: the study was supported by grants from the Swedish Council for Social Research (no 97-0329:1B), from the Academy of Finland (no 37487) and from the Swedish Medical Research Council (no K2000-27X-13434-01).

Conflicts of interest: none.

Authors' affiliations

N Hammar, U Hagström, L Alfredsson, Division of Epidemiology, Institute of Environmental Medicine, Karolinska institutet, Stockholm, Sweden

J Kaprio, Department of Public Health, University of Helsinki, Helsinki, Finland

M Koskenvuo, Department of Public Health, University of Turku, Turku, Finland

T Hammar, Centre for Research in International Migration and Ethnic Relations, University of Stockholm, Stockholm, Sweden 


\section{REFERENCES}

1 Robertson TL, Kato H, Rhoads GG, et al. Epidemiological studies of coronary heart disease and stroke in Japanese men living in Japan, Hawaii and California. Am J Cardiol 1977;39:239-43.

2 Rogot E. Cardiorespiratory disease mortality among British and Norwegian migrants to the United States. Am J Epidemiol 1978;108:181-91.

3 Salmond CE, Prior IAM, Wessen AF. Blood pressure patterns and migration: a 14-year cohort study of adult Tokelauans. Am J Epidemiol $1989 \cdot 130: 37-52$

4 Keil JE, Britt RP, Weinrich MC, et al. Hypertension in Punjabi females: comparison between migrants in London and natives in India. Hum Biol 1980;52:423-33.

5 Green MS, Etzion T, Incha E. Blood pressure and serum cholesterol among male Ethiopian immigrants compared to other Israelis. J Epidemiol Community Health 1991;45:281-6.

6 Rosenthal T, Grossman E, Knecht A, et al. Blood pressure in Ethiopian immigrants in Israel: comparison with resident Israelis. J Hypertens 1989;7 (suppl 1):S53-5.

7 Krupinski J. Changing patterns of migration to Australia and their influence on the health of migrants. Soc Sci Med 1984;18:927-37.

8 Nordic medico-statistical committee (NOMESCO). Health trends in the Nordic countries. Annus Medicus 1990. NORD 1990:99E. Copenhagen: NOMESCO, 1990.

9 Swedish National Board of Health and Welfare (NBHW). Health and social conditions among immigrants. [In Swedish.] NBHW report 1995:5. Stockholm: NBHW, 1995.

10 Sundquist J, Johansson S-E. The influence of country of birth on mortality from all causes and cardiovascular disease in Sweden 1979-1993. Int J Epidemiol 1997;26:279-87.
11 De Faire U, Arvidsson A, Bolander A-M. Mortality from ischaemic heart disease among Finnish immigrants in Sweden. Nordic Council Arct Med Res Report No 19 1977;29-31.

12 Alfredsson L, Ahlbom A, Theorell T. Incidence of myocardial infarction among male Finnish immigrants in relation to length of stay in Sweden. Int J Epidemiol 1982;11:225-8.

13 Razum O, Zeeb H, Ákgun HS, et al. Low overall mortality of Turkish residents in Germany persists and extends into a second generation: merely a healthy migrant effect? Trop Med Int Health 1998;3:297-303.

14 Swerdlow AJ. Mortality and cancer incidence in Vietnamese refugees in England and Wales: a follow-up study. Int J Epidemiol 1991;20:13-19.

15 Williams R. Health and length of residence among South asians in Glasgow: a study controlling for age. J Public Health Med 1993;15:52-60.

16 Kaprio J, Sarna S, Koskenvuo M, et al. The Finnish Twin Registry: Formation and compilation, questionnaire study, zygosity determination procedures and research program. Prog Clin Biol Res 1978;24B:17984.

17 Kaprio J. Lessons from twin studies in Finland. Ann Med 1994;26:135-9.

18 Rose GA, Blackburn H. Cardiovascular survey methods. World Health Organisation Monograph Series no 56. WHO: Geneva 1968.

19 Johansson LA Gjertsen F. Draft minutes of the Nordic-Baltic Mortality Meeting. Stockholm, Sweden 1-2 February, 2001. Newsletter. Stockholm: Nordic WHO Collaborating Centre for the Classification of Diseases, April 2001.

20 Esser $\mathbf{H}$. Aspects of migration sociology. Assimilation and integration among migrants, ethnic groups and minorities. [In German]. Luchterhand: Darmstadt und Neuwwied, 1980.

21 Castles S, Miller M. The age of migration. International population movements in the modern world. London: Macmillan, 1993 